\title{
Maternal and congenital syphilis in rural Haiti
}

\author{
Chaylah J. Lomotey, ${ }^{1,2}$ Judy Lewis, ${ }^{1,2,3,4}$ Bette Gebrian, ${ }^{1,5}$ \\ Royneld Bourdeau, ${ }^{5}$ Kevin Dieckhaus, ${ }^{2,6}$ and Juan C. Salazar ${ }^{1,2,4}$
}

Suggested citation Lomotey CJ, Lewis J, Gebrian B, Bourdeau R, Dieckhaus K, Salazar JC. Maternal and congenital syphilis in rural Haiti. Rev Panam Salud Publica. 2009;26(3):197-202.

ABSTRACT Objectives. A study was conducted to assess the prevalence of maternal syphilis and estimate the rate of congenital syphilis in five rural villages surrounding Jeremie, Haiti.

Methods. This research was a retrospective observational study. Data were extracted from the Haitian Health Foundation's public health database and verified through original clinical paper records, death certificates, midwife reports, and discussions with community health workers. Data were analyzed by chi-square analysis, bivariate correlations, and two-tailed $\mathrm{t}$-test for independent samples.

Results. Of the 410 women tested for syphilis, 31 (7.6\%) were sero-reactive. Average gestation at time of testing was 25 weeks, which correlated with entry into prenatal care at an average of 23 weeks. Women who tested positive during pregnancy were more likely to have had a negative pregnancy outcome than those who did not (chi square $=16.4 ; \mathrm{P}<0.0001$ ). The estimated rate of congenital syphilis in the region was 767 per 100,000 live births.

Conclusions. Maternal syphilis is prevalent in rural Haiti. This prevalence combined with late entry into prenatal care contributes to adverse pregnancy outcomes and a high estimated rate of congenital syphilis. More research is needed on congenital syphilis and prenatal-careseeking practices of rural Haitian women in order to understand the impact of maternal syphilis in the region and improve pregnancy outcomes.

Key words Syphilis, congenital; syphilis; pregnancy complications, infectious; Haiti.

Syphilis continues to be a widespread global health problem, affecting 12 mil-

\footnotetext{
1 University of Connecticut Graduate Program in Public Health, Farmington, Connecticut, United States of America. Send correspondence and reprint requests to Chaylah Lomotey, john3_16_17@hotmail.com

2 University of Connecticut, School of Medicine, Farmington, Connecticut, United States of America.

3 University of Connecticut, Department of Community Medicine and Health Care, Farmington, Connecticut, United States of America.

4 University of Connecticut, Department of Pediatrics, Farmington, Connecticut, United States of America. Haitian Health Foundation, Jeremie, Haiti.

6 University of Connecticut, Department of Medicine, Farmington, Connecticut, United States of America.
}

lion people each year and resulting in significant morbidity and mortality (1). SubSaharan Africa has the highest prevalence of gestational syphilis, with up to $17 \%$ of pregnant women testing positive for syphilis at antenatal clinics (2). Several Latin American and Caribbean countries, including Haiti, also have very high reported rates of the disease $(3,4)$. Congenital syphilis rates closely parallel rates of primary and secondary syphilis in women of child-bearing age (5).

Syphilis in pregnancy is a major risk for the mother and the fetus, frequently causing miscarriage, stillbirth, and neonatal death (6). Adverse pregnancy out- comes are known to occur in up to $80 \%$ of women with active syphilis during gestation (7). Congenital syphilis, particularly if untreated, usually causes deleterious consequences to the child-including deafness, blindness, and mental retardation. Given that $50 \%$ of infants with congenital syphilis are asymptomatic at birth (8), many such children born to women with unrecognized gestational syphilis could remain untreated. Early prenatal screening for syphilis, and proper treatment of women during pregnancy, is therefore the most costeffective approach to avoid prenatal complications and the high morbidity 
associated with congenital syphilis (9, 10). Both the Centers for Disease Control and Prevention (CDC) and the World Health Organization (WHO) strongly recommend that all pregnant women, regardless of where they live, be tested for syphilis in the early stages of pregnancy or on the first prenatal visit $(11,12)$. It is also recommended that they receive timely and appropriate penicillin treatment in the event they have serologic evidence of syphilis.

There is little published information on the prevalence of gestational and the incidence of congenital syphilis in the Caribbean nation of Haiti, especially in rural areas of the country. Available data from a CDC-sponsored syphilis seroprevalence study in 2003-2004 determined that the overall gestational syphilis rate in Haiti was 3.7\% (13). A more recent study showed that the rate has remained high $(3.6 \%)$ and that in one particular region of Haiti, Jeremie, an even greater proportion (6\%) of pregnant women have serologic evidence of syphilis (4). Two of the very few studies done on gestational syphilis in rural Haiti include those performed in the north central Artibonite region of Haiti $(14,15)$. The studies show the gestational syphilis rates in that rural area of the island also to be close to $6 \%$ (14). How gestational syphilis adversely affects Haitian women and their offspring in rural regions of the country has not been properly studied. This investigation was therefore designed to measure the prevalence of gestational syphilis in a region of rural Haiti and, more precisely, to determine pregnancy outcomes for women who have serologic evidence of gestational syphilis.

\section{MATERIALS AND METHODS}

\section{Overview}

We conducted a retrospective observational study in rural Haiti to determine the prevalence of gestational and congenital syphilis as well as the outcome of such pregnancies. Study outcomes were based on secondary data obtained from the Haitian Health Foundation's (HHF) rural public health and clinical databases. All study procedures were reviewed and approved by the HHF Research Review Committee and the Institutional Review Board at the University of Connecticut Health Center.

\section{Study site}

HHF is a nongovernmental organization with headquarters in Norwich, Connecticut, United States of America, and program offices, clinics, and rural public health programs based in Jeremie, Haiti. HHF began work in Jeremie in 1986 and has focused on providing high-quality maternal and child health care. HHF has clinics and a rural public health program, which have participated in sentinel CDC syphilis seroprevalence studies cited above. Prenatal services at HHF facilities include gestational syphilis testing and treatment.

HHF's rural public health program is based on a census and registration system that ensures that all members of communities are identified and provided with care. Currently, there are 104 villages in the census, with a total of 200000 residents. Primary services are provided by community health workers (CHWs or agents de santé). CHWs are selected by their villages, trained in a governmentapproved curriculum, and supported and supervised by HHF through funding by private sources and the United States Agency for International Development. CHWs live in the villages, where they provide accessible preventive and curative care to 2 000-3 000 people. A key element of this census-based registration system is Public Health Active Census Tracking (PHACT), a computerized public health database. PHACT maintains household and individual information, including information about each individual, family unit, and household with a unique numeric identifier. Information housed in the database includes demographic information, socioeconomic indicators, immunization status, maternal and child weights, pregnancy history, prenatal care, birth outcomes, and child spacing.

Although HHF has conducted syphilis testing for many years, these results were only recently added to PHACT (2006). Rural testing began in 2001 with a rapid treponemal assay (Determine-TP) (16). This test takes 10-15 minutes, so women who test positive are able to receive the first dose of intramuscular penicillin treatment on the day of testing. The Determine-TP rapid test (Inverness, Waltham, Massachusetts, United States of America) has been validated in several studies as an appropriate screening tool for low-resource areas (17-20).
Rapid point-of-care syphilis testing during pregnancy has been studied in Haiti and has been shown to be very cost-effective (10). The HHF treatment regimen at the time of this study was two doses of benzathine penicillin, 2.4 million units intramuscularly, given 8 days apart (see below for current treatment regimen). At the time of the second injection, affected women were asked to bring their partners for treatment to prevent reinfection.

\section{Study procedures}

A sample of five rural HHF villages included in the census was selected for the study. These localities were chosen based on two criteria: length of time associated with HHF and number of pregnancies in 2004-2006. One village was in Moron County, and the other four were in Jeremie County. These criteria were used to provide a representative sample of women from the HHF service area.

Paper prenatal records were collected for all women in the sample villages who were pregnant and delivered in 2004-2006. According to a comparison with the PHACT database, approximately $10 \%$ of the paper prenatal records could not be found because they were lost or destroyed. Syphilis test dates, results, and treatment were entered into PHACT for the 507 prenatal records that were located. Women with a known history of treated syphilis were to be excluded from the study; however, no women met this criterion.

Pregnancy outcome was established from existing records in the PHACT database. Additional verification was done by examining all available $\mathrm{HHF}$ death certificates and midwife reports for the study period. In addition, community health agent interviews for the villages were used to verify miscarriages, stillbirths, and neonatal deaths.

\section{Case definition}

For the purpose of this study, a woman was considered to have gestational syphilis if she had a reactive rapid treponemal test and no prior treatment for syphilis during the pregnancy. Congenital syphilis was defined according to CDC criteria (see Table 1) (21), which are based principally on maternal syphilis serologic status and whether the woman received appropriate treatment. Physical 
examination results were not available for infected infants because they are not routinely examined in the rural communities where they are delivered. Serologic nontreponemal assays (i.e., rapid plasma reagin (RPR)) and cerebrospinal examination were not routinely done for these infants.

\section{Statistical analysis}

The data were extracted from PHACT and analyzed in SPSS Version 12.0 (Chicago, Illinois, United States of America) using chi-square measures of association, two-tailed $t$-test for independent samples, and bivariate correlations. A value of $P \leq 0.05$ was considered significant.

\section{RESULTS}

\section{Demographics}

The total population of selected villages ranged from 1600 to 3100 , and the proportion of women of reproductive age ranged from $20 \%$ to $27 \%$. A total of 507 women, ranging in age from 14 to 49 years, with a mean age of 28.6 years, were included in the study. Socioeconomic status of the women was represented by two house construction variables (number of rooms and roof type) using a previously validated scale (22). Of the 507 women, 450 had socioeconomic data available. The number of rooms ranged from 1 to 5 with a mean of 2.5 (standard deviation (SD) 0.72); 66\% of women had tin roofs, a marker of higher socioeconomic status, and the rest had thatched roofs. Most women (72.3\%) indicated they had a mari, a Kreyol word that may mean legal marriage but more commonly means cohabitation with a male partner.

\section{Gestational syphilis}

Most women included in the study $(81 \%$, No. $=410)$ underwent serologic testing for syphilis. From this group, 31 $(7.6 \%)$ had a reactive treponemal test. All women who had a positive test had evidence of treatment. There was no significant difference in gestational syphilis prevalence rates by village. Although 410 women were tested, clear documentation of the time during pregnancy when they were tested was available for only 350 ( $85 \%$ of those tested). On aver-

TABLE 1. Centers for Disease Control and Prevention case definition of congenital syphilis

A case of congenital syphilis is defined as:

A condition affecting an infant whose mother had untreated or inadequately ${ }^{a}$ treated syphilis at delivery regardless of physical findings in the infant

An infant or child who has a reactive treponemal test

An infant or child with any physical or other evidence of congenital syphilis

Syphilitic stillbirth (stillbirth occurring to a woman with untreated or inadequately ${ }^{\text {a }}$ treated syphilis)

Source: Information taken from reference 21

a Inadequate treatment refers to any nonpenicillin therapy or penicillin given less than 30 days before delivery.

age, women were tested in the 25 th week of pregnancy (SD 7.7 weeks). Only about $11 \%($ No. $=38)$ of the 350 women were tested in the first trimester, another $60 \%$ $($ No. $=210)$ were tested in the second trimester, and close to $29 \%($ No. $=102)$ were tested in the third trimester. The time in gestation when women were treated was available for only 24 of the 31 women who had a positive treponemal test. Two of the $24(8 \%)$ were tested and treated during the first trimester, $46 \%($ No. $=11)$ were tested and treated in the second trimester, and $46 \%($ No. $=11)$ were tested and treated in the third trimester. Approximately 11\% (No. = 37) of all pregnant women were tested within 30 days of delivery; 3 of them had serologic evidence of syphilis.

There was a significant relationship between adverse pregnancy outcomes and maternal syphilis status. Adverse outcomes included miscarriages, stillbirths, and neonatal deaths. All adverse outcomes were recorded as one variable in the data set and could not be separated for analysis. There were 6 adverse outcomes in the syphilis-positive group (19.4\%) and $13(3.4 \%)$ in the syphilis-negative group (chi square $=16.4 ; P<0.0001$ ). Figure 1 provides a summary of test results, treatment, and birth outcomes.

\section{Congenital syphilis}

We determined that 3 infants met the case definition of congenital syphilis out of 391 live births (Table 1) (21). All 3 infants were born to women who tested positive for syphilis and were either inadequately treated or received treatment within 30 days of delivery. One of the three infants died at delivery, most likely as a result of congenital syphilis. On the basis of these numbers, we estimate that the congenital syphilis rate for rural Jeremie is approximately 767 cases per 100000 live births. This rate is no doubt very high but grossly underestimates the magnitude of the problem, as many offspring likely die in utero before delivery.

\section{DISCUSSION}

This study demonstrates that a significant proportion of pregnant women in rural villages surrounding Jeremie have serologic evidence of syphilis. The seroprevalence rate is significantly higher than the established rate previously determined for the entire country $(4,13)$. It is possible, but unlikely, that serologic evidence for syphilis represents infection with one of the nonvenereal endemic treponematoses, such as yaws. This uncertainty is plausible because venereal syphilis and the endemic treponematoses are serologically indistinguishable (23). Although a global elimination campaign for yaws and other endemic treponematoses in the 1950s virtually eliminated the disease, there was a resurgence in some areas in the 1970s (24). Unfortunately, little is known about the current prevalence of these diseases in Haiti. Endemic treponematoses, however, are not vertically transmitted (25); thus, one would not expect to see the relationship between adverse pregnancy outcomes and a positive treponemal assay found in this study if the high prevalence were due to one of the endemic treponematoses. Further research is needed to help elucidate the social, cultural, and epidemiologic factors that may contribute to the regional variations in prevalence.

This study also demonstrates a clear relationship between gestational syphilis and adverse pregnancy outcomes in this rural region of Haiti. It is possible that testing positive for syphilis may only be a marker for other factors that might influence pregnancy outcome, such as poor overall health, HIV status, and low socioeconomic status. However, it is likely that the relationship is causal, as 
FIGURE 1. Summary of test results, treatment, and birth outcomes

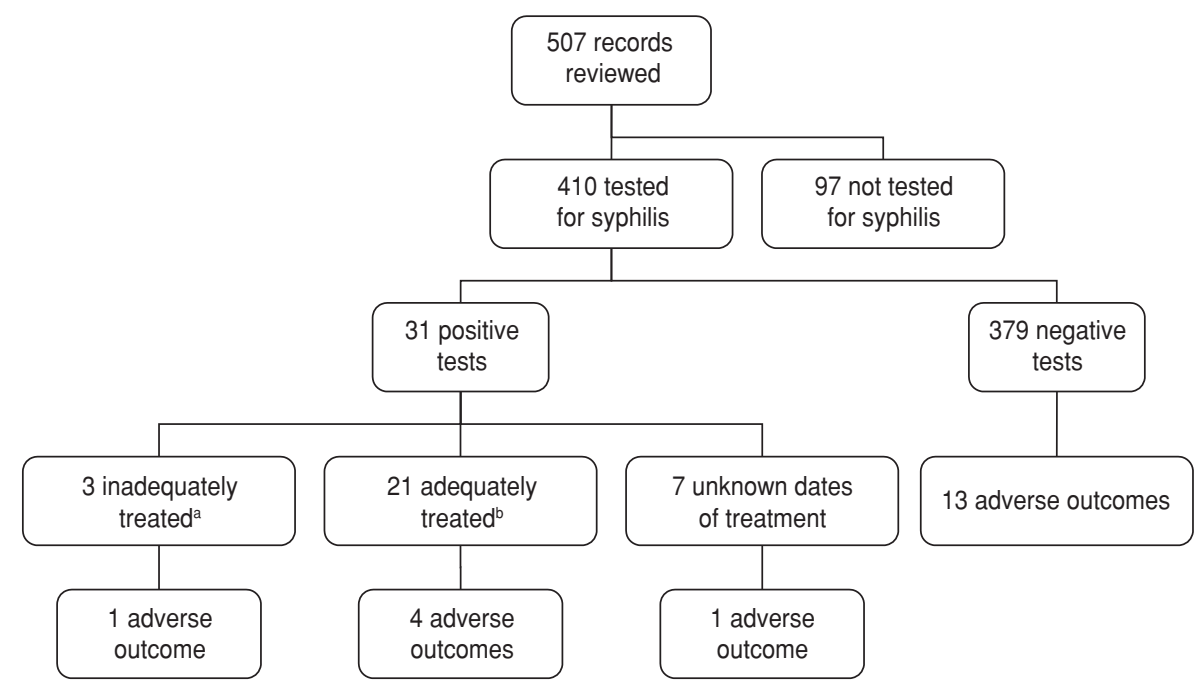

a Inadequate treatment refers to any nonpenicillin therapy or penicillin given less than 30 days before delivery (22).

${ }^{\mathrm{b}}$ At the time of this study, all women in the Haitian Health Foundation (HHF) with a positive syphilis test were being treated with two doses of intramuscular benzathine penicillin 1 week apart. The Centers for Disease Control and Prevention recommends that all cases of primary, secondary, and early latent syphilis be treated with a single intramuscular dose of benzathine penicillin, while cases of tertiary and late latent syphilis should be treated with three intramuscular doses of benzathine penicillin given weekly (11). The HHF procedure at the time of this study did not include clinical staging; all women were treated uniformly with two doses of penicillin.

syphilis is known to adversely affect fetuses (6). Though treatment of gestational syphilis significantly decreases the risk of adverse pregnancy outcomes, women with syphilis during pregnancy are 2.5 times more likely to have adverse outcomes than women who were not infected at any time during pregnancy, even after treatment (26). A prospective cohort or case-control study controlling for variables such as HIV status and overall health might help to delineate this relationship more clearly.

Delay in initiating prenatal care is clearly a major barrier to reducing the rates of maternal and congenital syphilis in this area. Women in this study were found to enter prenatal care at an average of 23-25 weeks of gestation, which is much later than has been recommended by WHO (12). Possible reasons for this delay are lack of knowledge about the need for early prenatal care, social and financial costs of leaving marketing or agricultural work to attend visits, desire to keep pregnancy a secret in early stages, and lack of confirmation of pregnancy. Of even greater concern, $11 \%$ of women in this study were tested within only 30 days of delivery. This circumstance is important because the highest risk for congenital syphilis, or syphilitic stillbirth, occurs when a woman is treated within 30 days of delivery (27). More research is needed to understand the prenatal-care-seeking practices of rural Haitian women, and increased efforts are needed to educate women about the importance of early prenatal care.

The true magnitude of congenital syphilis has not been well documented in rural Haiti. The only congenital syphilis prevalence data available for rural Haiti are from studies in the Artibonite Valley, which showed a congenital syphilis rate of 550 cases per $100000(14,15)$. On the basis of our current findings, we estimate a rate of 767 cases of congenital syphilis per 100000 live births, which clearly indicates that the disease represents a critical public health problem that remains underrecognized and undertreated in this population. As a result of this research, HHF has begun testing and treating all infants born to syphilispositive mothers as recommended by the WHO congenital syphilis elimination program $(1,5)$. Testing at the urban HHF center in Jeremie uses a nontreponemal serologic test (RPR). Although the RPR assay likely yields many false positives (5), more specific treponemal tests gener- ally have not been available in this lowresource setting. Treatment for syphilispositive infants consists of a single intramuscular dose of penicillin per the $\mathrm{WHO}$ protocol (5), unless the child is symptomatic-in which case the infant is referred to the local hospital. Because of the well-known effects of syphilis in pregnancy combined with the high percentage of women affected in rural Haiti, both governmental and nongovernmental organizations working in rural Haiti should develop programs to help decrease the burden of syphilis.

It is important to highlight that our study findings are limited for two important reasons. First, the relatively small sample size does not allow us to differentiate between the effects of gestational syphilis and other known contributing factors to negative pregnancy outcomes. This situation requires a prospective study and a multivariate analysis. Second, it is recognized that an important limitation of treponemal tests is that they can remain positive even after proper treatment for syphilis has been provided. Thus, someone previously treated for syphilis may be misdiagnosed as having a new, untreated case if only a treponemal test is used (16). To address the latter, women in the HHF censused villages who have a positive Determine-TP rapid test are now being referred to Jeremie for confirmatory RPR and an HIV test. Such data were not available for this study.

The findings in this study have provided the basis for proposed changes in the HHF syphilis program and for developing recommendations for the Haitian Ministry of Public Health and Population (MSPP). Changes in the HHF syphilis program already include the initiation of testing and treatment of neonates born to syphilis-positive mothers and changing the treatment protocol for gestational syphilis of unknown duration in pregnant women from two doses of penicillin to three to be consistent with CDC treatment recommendations (11). In addition, HHF is placing greater emphasis on increasing the percentage of women who are screened for syphilis and providing education about the importance of early prenatal care and early syphilis screening. Specific recommendations being made to the Haitian MSPP include the following: (1) to make universal gestational syphilis screening and 
treatment more accessible in rural Haiti by providing rapid syphilis tests or laboratory supplies for the RPR to rural dispensaries and to ensure there is a continuous stock of penicillin at all rural and urban clinics, (2) to initiate universal testing and treatment of neonates born to syphilis-positive mothers as recommended by the WHO Congenital Syphilis Elimination Campaign, and (3) to undertake national education campaigns about the importance of early prenatal care.

In conclusion, this study demonstrates that maternal syphilis is highly prevalent in the rural areas surrounding Jeremie, Haiti. This high prevalence combined with late entry into prenatal care results in poor pregnancy outcomes as well as a very high incidence of congenital syphilis. Clearly, maternal and congenital syphilis are underrecognized in this region of Haiti, and there is a need for increased program interventions and public education to reduce the burden of this preventable disease. Future studies should be done on a larger number of villages, examining risk factors for gestational syphilis, documenting barriers to early prenatal care by using ethnographic methods, and having more in-depth documentation of congenital syphilis.

\section{REFERENCES}

1. World Health Organization. The global elimination of congenital syphilis: rationale and strategy for action. Geneva: WHO; 2007. Available from: http://www.who.int/ reproductive-health/publications/congenital_ syphilis/strategy_congenitalsyphilis.pdf. Accessed 10 August 2008.

2. Watson-Jones D, Oliff M, Terris-Prestholt F, Changalucha J, Gumodoka B, Mayaud P, et al. Antenatal syphilis screening in sub-Saharan Africa: lessons learned from Tanzania. Trop Med Int Health. 2005;10(9):934-43.

3. Valderrama J, Bautista MAU, Orlich GG, Siri RS, Osimani ML, Abreu H, et al. Maternal and congenital syphilis: case definitions. Epidemiol Bull. 2005;26(1):12-5. Available from: http:// www.paho.org/english/dd/ais/be_v26n1en-sifilis.htm\#ref. Accessed 10 August 2008.

4. Ministère de la Santé Publique de la Population Institut Haitien de l'Enfance, Centres GHESKIO, Centers for Disease Control and Prevention. Etude de sero surveillance par méthode sentinelle de la prévalence du VIH, de la syphilis, de l'hépatite $B$ et de l'hépatite $C$ chez les femmes enceintes en Haiti 2006/2007. Port $\mathrm{Au}$ Prince, Haiti: Centers for Disease Control and Prevention; 2007.

5. Saloojee H, Velaphi S, Goga Y, Afadapa N, Steen $R$, Lincetto $R$. The prevention and management of congenital syphilis: an overview and recommendations. Bull World Health Organ. 2004;82(6):424-30. Available from: http://www.scielosp.org/scielo.php?script= sci_arttext\&pid=S0042-96862004000600007. Accessed 10 August 2008.

6. Jenson HB, Baltimore RS. Pediatric infectious diseases: principles and practice. 2nd ed. Philadelphia: W. B. Saunders Company; 2002.

7. Schmid GP, Stoner BP, Hawkes S, Broutet N. The need and plan for global elimination of congenital syphilis. Sex Transm Dis. 2007;34 Suppl 7:S5-10.

8. Rydzak CE, Goldie SJ. Cost-effectiveness of rapid point-of-care prenatal syphilis screening in sub-Saharan Africa. Sex Transm Dis. 2008;35(9):775-94.

9. World Bank. World development report 1993: investing in health. New York: World Bank; 1993.

10. Schackman BR, Neukermans CP, Fontain SN, Nolte C, Joseph P, Pape JW. Cost-effectiveness of rapid syphilis screening in prenatal HIV testing programs in Haiti. PLoS Med. 2007; 4(5):937-47.

11. Centers for Disease Control and Prevention. Sexually transmitted diseases treatment guidelines 2006: congenital syphilis. MMWR Morb Mortal Wkly Rep. 2006;55(11):No. RR-11. Available from: http://www.cdc.gov/std/ treatment/2006/congenital-syphilis.htm. Accessed 10 August 2008.

12. Department of Making Pregnancy Safer, World Health Organization. Prevention of mother to child transmission of syphilis: integrated management of pregnancy and childbirth. Geneva: WHO; 2006. Available from: http://www.who.int/making_pregnancy_ safer/publications/Standards1.3N.pdf. Accessed 10 August 2008.

13. Ministère de la Santé Publique de la Population, Institut Haitien de l'Enfance, Centres GHESKIO, Centers for Disease Control and Prevention. Etude de sero surveillance par méthode sentinelle de la prévalence du VIH, de la syphilis, de l'hépatite $B$ et de l'hépatite $C$ chez les femmes enceintes en Haiti 2003/2004. Port $\mathrm{Au}$ Prince, Haiti: Centers for Disease Control and Prevention; 2004.

14. Fitzgerald DW, Freida MTB, Lucet C, Roberforoid D. Prevalence, burden, and control of syphilis in Haiti's rural Artibonite region. Int J Infect Dis. 1998;2(3):127-31.

15. Desormeaux J, Behets FM, Adrien M, Coicou G, Dallabetta G, Cohen M, et al. Introduction of partner referral and treatment for control of sexually transmitted diseases in a poor Haitian community. Int J STD AIDS. 1996;7(7): 502-6.

16. Diaz T, Almeida MG, Georg I, Maia SC, de Souza RV, Markowitz LE. Evaluation of the Determine Rapid Syphilis TP assay using sera. Clin Diagn Lab Immunol. 2004;11(1):98-101.

17. Mabey D, Peeling RW, Ballard R, Benzaken AS, Galban E, Changalucha J, et al. Prospective, multi-center, clinic-based evaluation of four rapid diagnostic tests for syphilis. Sex Transm Infect. 2006;82 Suppl 5:13-6.

18. Lien TX, Tien NT, Chanpong GF, Cuc CT, Yen VT, Soderquist R, et al. Evaluation of rapid diagnostic tests for the detection of human immunodeficiency viruses type 1 and 2, hepatitis B surface antigen, and syphilis in Ho Chi
Minh City, Vietnam. Am J Trop Med Hyg. 2000;62(2):301-9.

19. Angue Y, Yauieb A, Mola G, Duke T, Amoa AB. Syphilis serology testing: a comparative study of Abbot Determine, rapid plasma reagin (RPR) card test and Venereal Disease Research Laboratory (VDRL) methods. PNG Med J. 2005;48(3-4):168-73.

20. Herring AJ, Ballard RC, Pope V, Adegbola RA, Changalucha J, Fitzgerald DW, et al. A multi-centre evaluation of nine rapid, pointof-care syphilis tests using archived sera. Sex Transm Infect. 2006;82 Suppl 5:v7-12.

21. Centers for Disease Control and Prevention. Congenital syphilis case investigation and reporting form instructions, 2003. Atlanta, GA: CDC; 2003. Available from: http://www.cdc. gov/std/Program/ConSyphInstr11-2003. pdf. Accessed 10 August 2008.

22. Gebrian B. Community participation in primary care in rural Haiti: an ecological approach [PhD dissertation]. Storrs, CT: University of Connecticut; 1993.

23. Fine S, Fine LS. Treponematosis (endemic syphilis). Emedicine. 2006. Available from: http://www.imedicine.com. Accessed 10 September 2008

24. World Health Organization. Wkly Epidemiol Rec. 2008;83(9):77-88. Available from: http:// www.who.int/yaws/resources/WER_Feb_ 2008.pdf. Accessed 10 August 2008.

25. Antal GM, Lukehart SA, Meheus AZ. The endemic treponematoses: review. Microbes Infect. 2002;4:83-94.

26. Lubiganon P, Piaggio G, Villar J, Pinol A Bakketeig L, Bergsjo P, et al. The epidemiology of syphilis in pregnancy. Int J STD AIDS. 2002;13:486-94.

27. Sheffield JS, Sanchez PJ, Morris G, Maberry M, Zeray F, McIntire DD. Congenital syphilis after maternal treatment for syphilis during pregnancy. Am J Obstet Gynecol. 2002;186(3):569-73.

Manuscript received on 23 October 2008. Revised version accepted for publication on 22 March 2009. 
RESUMEN Objetivos. Evaluar la prevalencia de sífilis materna y estimar la tasa de sífilis congénita en cinco poblaciones rurales cercanas a Jeremie, Haití.

\section{Sífilis materna y congénita en zonas rurales de Haití}

Palabras clave
Métodos. Estudio observacional retrospectivo a partir de datos extraídos de la base de datos de salud pública de la Fundación Haitiana de Salud y verificada con los registros clínicos originales en papel, los certificados de defunción, los informes de las parteras y discusiones con los trabajadores comunitarios de salud. Los datos se analizaron mediante la prueba de la ji al cuadrado, correlaciones bifactoriales y la prueba de la $t$ de dos colas para muestras independientes.

Resultados. De las 410 mujeres sometidas a la prueba de sífilis, 31 (7,6\%) resultaron seropositivas. La edad gestacional promedio al momento de la prueba fue de 25 semanas, lo que se correlacionó con la edad gestacional de entrada a la atención prenatal (23 semanas). Las mujeres que resultaron seropositivas durante el embarazo presentaron mayor probabilidad de tener un desenlace negativo de su embarazo que las mujeres que resultaron seronegativas $\left(\chi^{2}=16,4 ; P<0,0001\right)$. La tasa estimada de sífilis congénita en la zona fue de 767 por 100000 nacidos vivos.

Conclusiones. La sífilis materna es frecuente en las zonas rurales de Haití, lo que combinado con la entrada tardía a los servicios de atención prenatal, contribuye a los desenlaces adversos de los embarazos y a la alta tasa estimada de sífilis congénita. Se requieren más estudios sobre la sífilis congénita y los hábitos de búsqueda de atención prenatal de las mujeres de zonas rurales de Haití para comprender el impacto de la sífilis materna en esta parte del país y mejorar el desenlace de los embarazos.

Sífilis; sífilis congénita; complicaciones infecciosas del embarazo; Haití.

\section{Esquemas de protección social para la población materna, neonatal e infantil: lecciones aprendidas de la Región de América Latina}

Este informe es producto de una iniciativa conjunta de la Organización Panamericana de la Salud (OPS/OMS), la Agencia de los Estados Unidos para el Desarrollo Internacional (USAID), la Agencia Sueca para el Desarrollo Internacional (ASDI) y la Agencia Española de Cooperación Internacional (AECI), iniciada en 2004/2005 con el objetivo de identificar opciones para extender protección social en salud a la población materna, neonatal e infantil en la región de ALC. Se apoya fuertemente en conceptos, metodologías, análisis y datos desarrollados y obtenidos por la OPS/OMS y la Agencia Sueca para el Desarrollo Internacional (ASDI) desde el año 2000 y en los desarrollos conceptuales de la Iniciativa Conjunta OPS-OIT en Extensión de Protección Social en Salud.

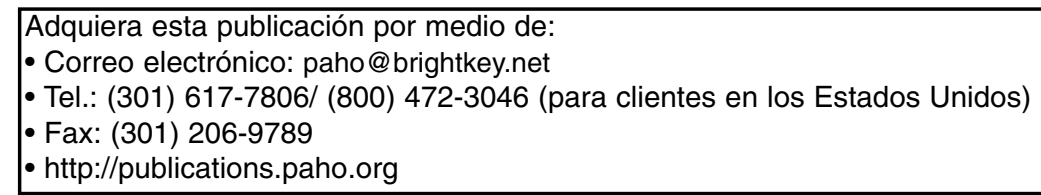

